\title{
Autoignition of Straight-Run Naphtha: A Promising Fuel for Advanced Compression Ignition Engines
}

\author{
Mohammed Alabbad ${ }^{1}$, Gani Issayev ${ }^{1}$, Jihad Badra*2, Alexander K. Voice ${ }^{3}$, Binod Raj Giri ${ }^{1}$, Khalil \\ Djebbi $^{1}$, Ahfaz Ahmed ${ }^{1}$, S. Mani Sarathy ${ }^{1}$, Aamir Farooq*1 \\ ${ }^{1}$ King Abdullah University of Science and Technology (KAUST), Clean Combustion Research \\ Center, Physical Sciences and Engineering Division, Thuwal 23955, Saudi Arabia \\ ${ }^{2}$ Fuel Technology Division, R\&DC, Saudi Aramco, Dhahran, Saudi Arabia \\ ${ }^{3}$ Aramco Research Center-Detroit, Aramco Services Company, 46535 Peary Ct., Novi, MI 48374, \\ USA \\ *Corresponding authors emails: jihad.badra@aramco.com; aamir.farooq@kaust.edu.sa
}

\begin{abstract}
Naphtha, a low-octane distillate fuel, has been proposed as a promising low-cost fuel for advanced compression ignition engine technologies. Experimental and modelling studies have been conducted in this work to assess autoignition characteristics of naphtha for use in advanced engines. Ignition delay times of a certified straight-run naphtha fuel, supplied by Haltermann Solutions, were measured in a shock tube and a rapid comparison machine over wide ranges of experimental conditions (20 and $60 \mathrm{bar}, 620-1223 \mathrm{~K}, \phi=0.5,1$ and 2). The Haltermann straight-run naphtha (HSRN) has research octane number (RON) of 60 and motor octane number (MON) of 58.3, with carbon range spanning C3 - C9. Reactivity of HSRN was compared, via experiments and simulations, with three suitably formulated surrogates: a two-component PRF (n-heptane/iso-octane) surrogate, a threecomponent TPRF (toluene/n-heptane/iso-octane) surrogate, and a six-component surrogate. All surrogates reasonably captured the ignition delays of HSRN at high and intermediate temperatures. However, at low temperatures $(\mathrm{T}<750 \mathrm{~K})$, the six-component surrogate performed the best in emulating the reactivity of naphtha fuel. Temperature sensitivity and rate of production analyses revealed that the presence of cyclo-alkanes in naphtha inhibits the overall fuel reactivity. Zero-dimensional engine simulations showed that PRF is a good autoignition surrogate for naphtha at high engine loads, however, the six-component surrogate is needed to match the combustion phasing of naphtha at low engine loads.
\end{abstract}




\section{Introduction}

The rapid increases in population and living standards in developing countries are expected to increase global demand for transportation energy at an annual rate of $1-1.5 \%$ through at least 2050 [1-4]. Despite strong growth in alternative energy, traditional petroleum-based fuels (gasoline, diesel and jet fuel) are expected to dominate the transportation energy portfolio, both for light- and heavy- duty applications [2-4]. In addition, there is ample evidence that sufficient crude reserves exist to meet this increased demand $[4,5]$. A major concern of the utilization of fossil fuels is the emission of greenhouse gases (GHG) which impose significant burden on our environment. As a result, regulatory authorities are enforcing stringent efficiency and emissions regulations on the transportation sector. Therefore, improving the fuel efficiency in the transportation sector can help reduce the global energy usage and minimize GHG emissions.

Various advanced compression ignition engines have been investigated as technologies that combine the best of gasoline and diesel engines. Combustion strategies such as homogeneous charge compression ignition (HCCI) [6], reactivity-controlled compression ignition (RCCI) [7-9], and partially-premixed compression ignition (PPCI) [10-13] have sought to combine the relatively simple design of gasoline engines and their after treatment systems and the higher efficiencies of diesel engines benefits. These engine technologies share some high-level characteristics even though the engine operating parameters such as timing and number of injections, fuel type, and air system requirements may differ. Compression ignition operation eliminates traditional engine knock observed in spark-ignition (SI) engines, and globally lean operation eliminates throttling losses. At the same time, greater mixing of fuel and air prior to combustion reduces soot production relative to the conventional mixing-controlled (diesel) combustion.

The specifications of the enabling fuel for this engine technology are not very obvious. Many fuels with varying physical and chemical properties, such as ignition quality, distillation curve and chemical compositions, have been considered in previous works. These include conventional gasoline [3, 14-18], conventional diesel [11, 14, 17-22], gasoline-diesel blends ("dieseline") [3, 21, 23-25], low-octane gasolines ("naphthas") [3, $10,12,14-16,26]$ and reference fuel blends (composed of iso-octane, n-heptane, toluene) $[3,14,16,27,28]$. Certain fuel properties could affect the performance of the engine 
because PPCI combustion is dependent on mixture stratification as well as chemical kinetics [29] .For example, some studies indicate that there are direct impacts of fuel distillation and aromatic content on the soot emissions of PPCI engines [21,30], while others report a minimal effect [31]. Nonetheless, most of the studies have shown that fuel reactivity, or homogeneous ignition delay, is an important factor in optimizing the performance of PPCI engines over wide range of operating conditions. Optimization of engine in computation fluid dynamic simulations requires the use of simpler surrogate mixtures which mimic the characteristics of real fuel. The surrogates for gasoline-like fuels range from simple binary or ternary mixtures of iso-octane, $\mathrm{n}$-heptane and toluene to more complex mixtures containing additional species such as n-butane, iso-pentane, cyclopentane, 1-hexene, 1-pentene, 1,2,4-trimethylbenzene, and others. Many studies are available in literature on surrogate formulation strategies to match the chemical characteristics of real fuels but most previous work was focused on gasoline and diesel [32].

Compared to commercial gasoline and diesel fuels, refinery streams such as petroleum naphtha with research octane numbers (RON) in the 50-80 range have recently been considered attractive alternatives to provide suitable chemical characteristics (longer ignition delay than diesel) in compression ignition engines. These naphtha fuels can be produced in the refinery at lower cost and result in decreased well-to-tank $\mathrm{CO}_{2}$ emissions. Hao et al. [33] found that compared with the conventional pathway, the low-octane fuel and gasoline compression ignition (GCI) pathway leads to a $24.6 \%$ reduction in energy consumption and a $22.8 \%$ reduction in GHG emissions.

These low-octane naphtha fuels have not been studied as much as gasoline and diesel fuels. The fundamental characterization of these fuels in terms of homogeneous ignition delay times, laminar flame speeds and speciation is scarce in literature. In fact, the only detailed autoignition study on a real naphtha stream was recently reported by KAUST [32]. Using shock tube and rapid compression machine, Javed et al. [32] measured the homogeneous ignition delay times of a light naphtha stream $(\mathrm{RON}=64)$ along with its primary reference fuel (PRF) and multi-component surrogates over wide ranges of pressures, temperatures and equivalence ratios. They found that the PRF surrogate had similar ignition delay times compared to light naphtha at high and intermediate 
temperatures. However, a more complex multi-component surrogate was required to match the ignition delay times of light naphtha at low temperatures.

The purpose of the current study is to understand the autoignition behavior of a straight-run naphtha stream with RON of 60 and MON of 58.3. Fuel reactivity is studied using a shock tube and a rapid compression machine at various pressures, temperatures and equivalence ratios which are relevant to the compression ignition engine operation mode. Simple (PRF, TPRF) and more complex (multi-components) surrogates are formulated and their ignition delay times are compared with those of the naphtha fuel. In addition, engine simulations are performed under different engine operating conditions to identify regimes wherein surrogate composition notably alters combustion behavior.

\section{Experimental Details}

\subsection{Fuel characterization and surrogate formulation}

The naphtha fuel used in this work was purchased from Haltermann Solutions, and is referred as Haltermann straight-run naphtha (HSRN). The certificate of analysis (CoA) and detailed hydrocarbon analysis (DHA) of the fuel are provided in the Supplementary Materials. The fuel primary contains C3 - C9 hydrocarbons and does not have any oxygenated species or olefins. The fuel comprises $75 \%$ (by mole) paraffinic species and approximately $15 \%$ naphthenes and $10 \%$ aromatics. The fuel's boiling point range is $32-$ $140{ }^{\circ} \mathrm{C}$ and has an average molecular weight of 92.4. The light naphtha studied by Javed et al. [32] primarily consisted of $n$ - and iso-paraffins, and had higher octane rating than the straight run naphtha used in the current work.

Measured ignition delay times of Haltermann straight-run naphtha (HSRN) are compared with measured and simulated ignition delay times of three surrogates over a range of temperatures, pressures and equivalence ratios. The surrogates are formulated based on the matching of various target properties; (i) a simple two-components surrogate matching the research octane number (RON) of HSRN, (ii) a three-component surrogate matching RON and MON of HSRN, (iii) a six-component surrogates matching RON, MON, H/C, average molecular weight, density, and carbon types.

The two-component PRF surrogate contains $60 \%$ iso-octane and $40 \%$ n-heptane by volume, and is referred as PRF 60. The three-component TPRF (toluene/n-heptane/isooctane) surrogate was formulated to match the RON and MON of the naphtha using the 
methodology proposed by Kalghatgi et al. [34], and is referred as TPRF 60. Studying PRF and TPRF surrogates provide guidance on the conditions (temperatures, pressures and equivalence ratios) under which such simple surrogates may be utilized to mimic the ignition properties of a complex real fuel such as HSRN. This is useful for performing computational fluid dynamic (CFD) simulations, which must use widely available reduced chemical kinetic mechanisms [12, 13, 35].

The six-component surrogate for HSRN is prepared following the approach presented by Ahmed et al. [36]. This methodology for surrogate fuel formulation involves selection of target properties and carries out an optimization routine on a set of pallet species to achieve the best match with selected target properties. The formulated surrogate consists of n-pentane, n-heptane, 2-methylhexane, 2,2,4-trimethylpentane, cyclopentane and toluene. Basic properties of these species are listed in Table S1 (Supplementary Materials). Octane numbers, RON and MON, of the six-component surrogates were calculated using linear-by-mole correlation, while density was predicted using Refprop [37] at $288 \mathrm{~K}$. The six-component surrogate is referred as MCS (multi-component surrogate) in the remainder of the manuscript.

The properties of HSRN, PRF 60, TPRF 60 and the MCS surrogates are listed in Table 1. The RON and MON of HSRN were measured in a CFR (Cooperative Fuel Research) engine at the Saudi Aramco's Research and Development facility in Dhahran, Saudi Arabia using relevant ASTM methods.

\begin{tabular}{|l|l|lll|}
\hline & HSRN & PRF 60 & TPRF 60 & MCS \\
\hline RON & 60 & 60 & $60^{\mathrm{a}}$ & $60.5^{\mathrm{a}}$ \\
MON & 58.3 & 60 & $58.3^{\mathrm{a}}$ & $58.3^{\mathrm{a}}$ \\
Sensitivity (RON - MON) & 1.7 & 0 & 1.7 & 2.2 \\
H/C ratio & 2.147 & 2.264 & 2.175 & 2.139 \\
Avg. mol. wt. & 92.406 & 108.201 & 106.465 & 95.545 \\
& & & & \\
$n$-alkanes (mole\%) & 36.7 & 42.9 & 42.9 & 38.6 \\
iso-alkanes (mole\%) & 37.8 & 57.1 & 44.9 & 41.7 \\
Cycloalkanes (mole\%) & 15 & 0 & 0 & 8.7 \\
Aromatics (mole\%) & 10.5 & 0 & 12.2 & 11 \\
\hline
\end{tabular}


Table 1. Properties of Haltermann straight naphtha (HSRN) and its surrogates. Detailed compositions of the three surrogates are available in Table S2 (Supplementary materials). ${ }^{a}$ Calculated values.

\subsection{High-pressure shock tube facility}

Ignition delay times of Haltermann straight run naphtha (HSRN) were measured using the high-pressure shock tube (HPST) facility at King Abdullah University of Science and Technology (KAUST). The shock tube was heated $\left(95^{\circ} \mathrm{C}\right)$ to avoid any condensation on the internal wall of the shock tube. The mid-section of the shock tube houses two prescored aluminum diaphragms in a double diaphragm arrangement (DDA) which allows better control of the post-reflected shock conditions compared to a single diaphragm arrangement (SDA). The main difference between DDA and SDA is the diaphragm rupture timing. In SDA, gas pressure in the driver section is increased until the diaphragm ruptures. The breaking pressure depends on many variables such as diaphragm thickness, scoring depth, aluminum grade and rate of pressure increase. This makes it hard to precisely control the bursting pressure (P4) and ultimately the conditions (P5 and T5) behind reflected shock wave. In DDA, the mid-section is filled with bath gas pressure that is much lower than the breaking pressure of the diaphragm. Thereafter, the driver section is filled to the desired pressure $\mathrm{P} 4$. Breaking of the diaphragms is activated by suddenly venting the mid-section. This procedure allows precise control of post-shock conditions and required conditions can be easily reproduced.

Incident shock speed was measured by six PCB 113B26 piezoelectric pressure transducers (PZTs) placed in the last $3.7 \mathrm{~m}$ of the driven section of the shock tube. Incident shock attenuation rates varied from 0.5 to $1.8 \% / \mathrm{m}$. Shock jump relations and known thermodynamic parameters [38] were used to calculate the post-reflected shock conditions $\left(\mathrm{P}_{5}\right.$ and $\left.\mathrm{T}_{5}\right)$ with an uncertainty of $<1 \%$. Sidewall pressure trace was measured at 10.48 $\mathrm{mm}$ from the endwall. Electronically excited $\mathrm{OH}^{*}$ chemiluminescence at $307 \mathrm{~nm}$ was monitored through sapphire windows at the endwall and sidewall $(10.48 \mathrm{~mm}$ from the endwall) using UV-intensified photo-detectors. Qualitative fuel concentration-time history was measured using HeNe laser emitting at a wavelength of $3390 \mathrm{~nm}$. A schematic of the shock tube end-section is shown in Fig. 1. Details of the experimental facilities have been reported previously [39]. 


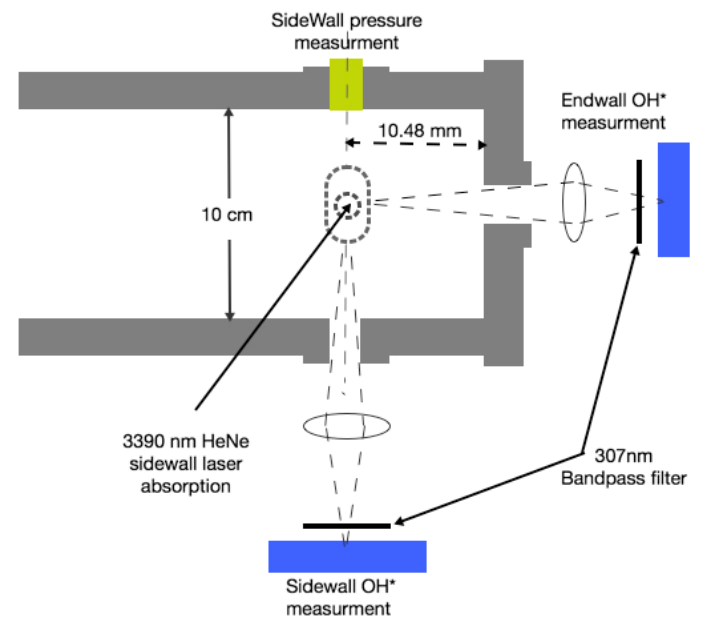

Fig. 1. Schematic of the optical configuration for ignition delay time measurements.

Test mixtures (fuel/oxidizer/diluent) were prepared in a heated $\left(140{ }^{\circ} \mathrm{C}\right)$ magnetically stirred mixing tank. After vacuuming the mixing tank to pressures less than $1 \times 10^{-2}$ mbar, liquid fuel was injected directly in the heated mixing tank. The injection was made through a septa rubber valve that has high sealing properties. Following fuel evaporation and pressure stabilization, vapor pressure was measured using an MKS pressure gauge $(0-100$ Torr range). Nitrogen and oxygen were added slowly to inhibit condensation of fuel that can lead to inaccuracies in the test mixture composition. Mixtures were left in the mixing vessel to homogenize for at least one hour prior to ignition experiments in the shock tube. Research-grade oxygen and nitrogen cylinders $(99.999 \%$ purity) were purchased from AH Gas Company. A molar ratio of 3.76:1 of $\mathrm{N}_{2}: \mathrm{O}_{2}$ was used to prepare fuel/air mixtures. Helium was used as the driver gas for ignition delay times less than $1.5 \mathrm{~ms}$. Driver gas tailoring (nitrogen in helium) and longer length of the driver section were used to achieve longer test times. A gradual pressure rise behind reflected shock wave, $\mathrm{dP}_{5} / \mathrm{dt}$, was observed, which was approximately $3 \% / \mathrm{ms}$ for non-tailored shocks and $2 \% / \mathrm{ms}$ for tailored shocks. These pressure rises were converted to volume profiles while performing ignition delay simulations in Chemkin-Pro.

Ignition delay time is defined as the time between the arrival of the reflected shock wave and the onset of the ignition near the endwall. The arrival of the reflected shock wave was determined by the step rise in pressure at the sidewall (10.48 $\mathrm{mm}$ from endwall) observation location. The onset of ignition was detected by the maximum slope in the 
sudden increase of pressure, $\mathrm{OH}^{*}$ at the endwall and sidewall or sudden change in fuel absorbance measured by the HeNe laser. All of these methods lead to very similar ignition delay times. Ignition delay data presented in this work were deduced from the pressure signal. Representative shock tube ignition delay time measurement is shown in Fig. 2(a). Uncertainty in the reported ignition delay times is estimated to be about $+/-15 \%$ and comes primarily from the uncertainty in the calculated reflected shock temperature.

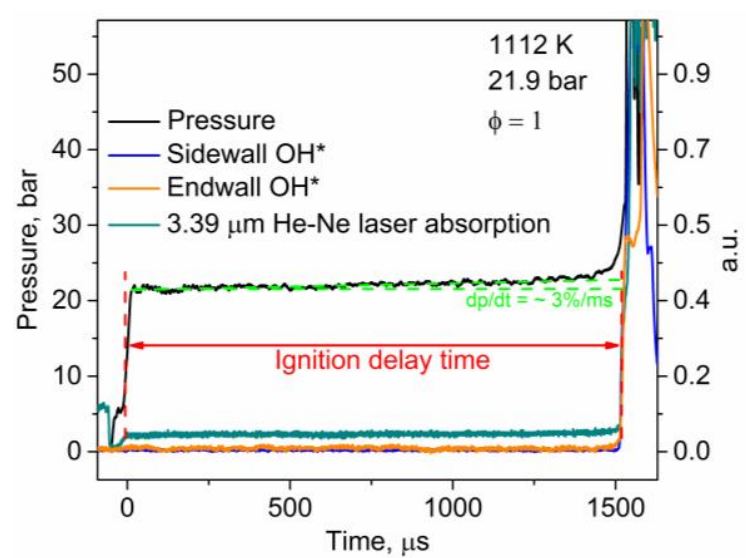

(a)

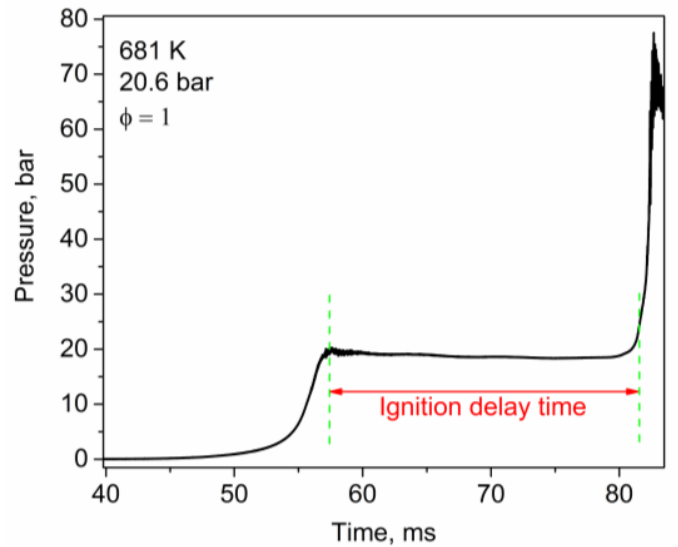

(b)

Fig. 2. A representative ignition delay times measurement for stoichiometric fuel/air. (a) shock tube (b) rapid compression machine.

\subsection{Rapid compression machine facility}

Ignition delay times at low temperatures were measured in the KAUST rapid compression machine (RCM) facility which has a twin-opposed piston configuration, similar to the machine at NUI Galway [40]. The KAUST RCM, however, has a larger chamber bore of $5.08 \mathrm{~cm}$, a stroke length of $16.9 \mathrm{~cm}$ and volumetric compression ratios of up to 16.8. Pressure profiles are recorded using a heat-shock resistant pressure transducer (Kistler 6045A). Further details of the RCM facility can be found elsewhere [32].

For RCM experiments, the ignition delay time is defined as the time between the end of compression and the maximum slope of the pressure rise due to ignition, as shown in Fig. 2(b). Ignition delay times were repeated three times for a single thermodynamic condition and the reproducibility of measured data is within $5 \%$ at similar compressed temperature 
and pressure. The compressed gas temperature, $\mathrm{T}_{\mathrm{C}}$, is calculated by employing the approximation with inputs of initial temperature, initial pressure, reactant composition, and the experimentally measured compressed gas pressure. The overall uncertainty in the measured ignition delay times is estimated to be $+/-15 \%$. In order to account for heat loss in the RCM, non-reactive experiments were performed for each studied condition. The pressure profiles measured in non-reactive experiments are imposed in the Chemkin-Pro simulations as volume profiles using the adiabatic relationship between pressure and density.

\section{Results and Discussion}

\subsection{Ignition Delay Time Measurements}

Ignition delay times were measured for Haltermann straight run naphtha (HSRN) and 'air' mixtures in the shock tube and rapid compression machine (RCM) over a range of engine relevant pressures (20 and 60 bar), temperatures $(620-1223 \mathrm{~K})$ and equivalence ratios $(0.5,1$ and 2). Ignition delay times spanning $100 \mu \mathrm{s}-6 \mathrm{~ms}$ were measured in the shock tube at two pressures (20 and 60 bar) and three equivalence ratios $(0.5,1$ and 2$)$. Ignition delay times spanning 3-430 ms were measured in the RCM at 20 bar and equivalence ratios of $0.5,1$ and 2. Additionally, ignition delay times of a diluted mixture of HSRN were measured to study the reactivity decrease with increased dilution. The dilution effect is essential for compression ignition engines since exhaust gas recirculation (EGR) is commonly used to control harmful NOx emissions. Ignition delay times of the PRF 60, TPRF 60 and MCS surrogates were also measured for comparison with the fuel ignition data and the chemical kinetic simulations. All experimental data are provided in tabular form in Table S4 (Supplementary Materials). Also, fuel/air mixture compositions are provided in Table S5 (Supplementary Materials)

Figure 3(a) shows the effect of pressure and equivalence ratio on the ignition delay times of HSRN/air mixtures measured in the shock tube. As expected, the ignition delay times decrease with increasing pressure. The effect of pressure in the NTC region is more pronounced compared to the high- and low- temperature regions. While moving from low to high pressures, the onset of NTC region gradually moves towards higher temperatures. 
Figure 3(a) also depicts the increase in reactivity when increasing the equivalence ratio from lean to rich $(\varphi=0.5$ to 2$)$. Similar to the pressure, the influence of equivalence ratio is more pronounced in the NTC region compared to the high- and low-temperature regions. In the NTC region, $\mathrm{R}+\mathrm{O} 2, \mathrm{RH}+\mathrm{OH}$ and $\mathrm{H}_{2} \mathrm{O}_{2}$ decomposition play critical role - all of these reactions are significantly influenced by the amount of fuel present and thus the equivalence ratio. Ignition delay data obtained in the RCM shows similar equivalence ratio dependence, as shown in Fig. 3(b). The influence of equivalence ratio decreases as temperature decreases from intermediate to low temperatures.

Ignition delay times of HSRN/air and a diluted mixture of HSRN are compared in Fig. 4 at a nominal pressure of 60 bar. As expected, the diluted mixture has longer ignition delay times than the non-diluted mixture. The effect of dilution is observed to be more significant in the NTC region. Increasing the nitrogen mole fraction by $\sim 7 \%$ compared to the fuel/air case, the ignition delay times are almost doubled in the NTC region. The observed reactivity change is mainly due to the decrease in the concentration of fuel and oxidizer.

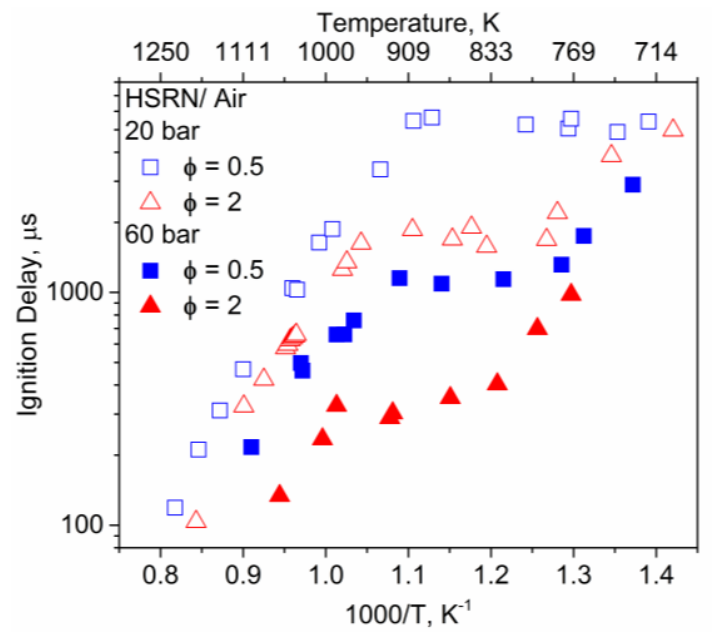

(a)

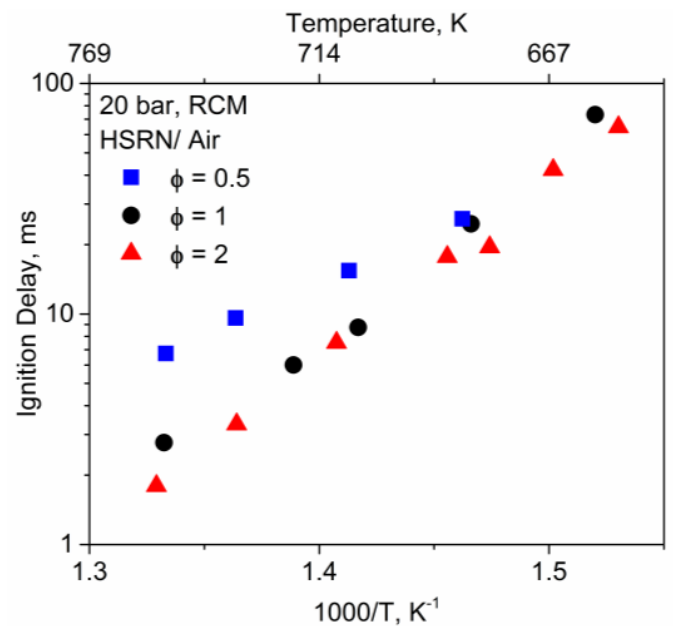

(b)

Fig. 3. Ignition delay times of HSRN/air measured in (a) Shock tube (b) RCM. 


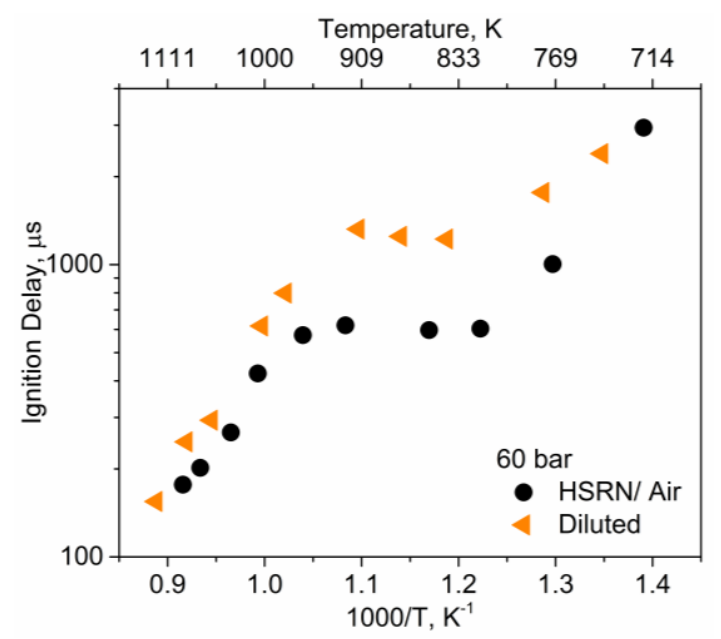

Fig. 4. Influence of dilution on ignition delay time of HSRN. Mixture composition for HSRN/air mixture: $2.05 \%$ fuel, $20.58 \% \mathrm{O}_{2}, 77.37 \% \mathrm{~N}_{2}$; diluted mixture: $1.4 \%$ fuel, $14 \%$ $\mathrm{O}_{2}, 84.6 \% \mathrm{~N}_{2}$.

Figure 5 shows a comparison between measured ignition delay times of HSRN and the three surrogates (PRF 60, TPRF 60 and MCS). Looking at the shock tube data at 60 bar and $\phi=1$ (Fig. 5(a)), it can be observed that the PRF 60 agrees very well with HSRN at high and intermediate temperatures. However, PRF 60 exhibits stronger NTC behavior and is more reactive than the naphtha at low temperatures. In order to elucidate the ignition delay time comparison at lower temperatures, rapid compression machine measurements of HSRN and the three surrogates were carried out at 20 bar and three equivalence ratios. Figure 5(b), only plotting stoichiometric data, shows that MCS (multi-component surrogate) matches the reactivity of HSRN better than the PRF 60 and TPRF 60 surrogates. The two simpler surrogates, PRF 60 and TPRF 60, exhibit similar reactivity and are consistently faster than HSRN at these low-temperature conditions. Further comparisons between HSRN and the MCS for lean and rich mixtures are shown in Fig. 5(c), and indicate very good agreement between the MCS and HSRN over the studied conditions. 


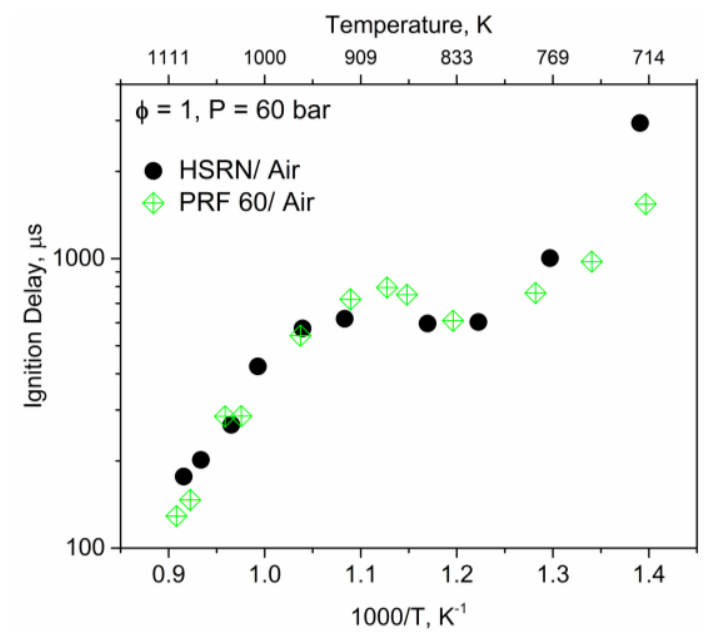

(a)

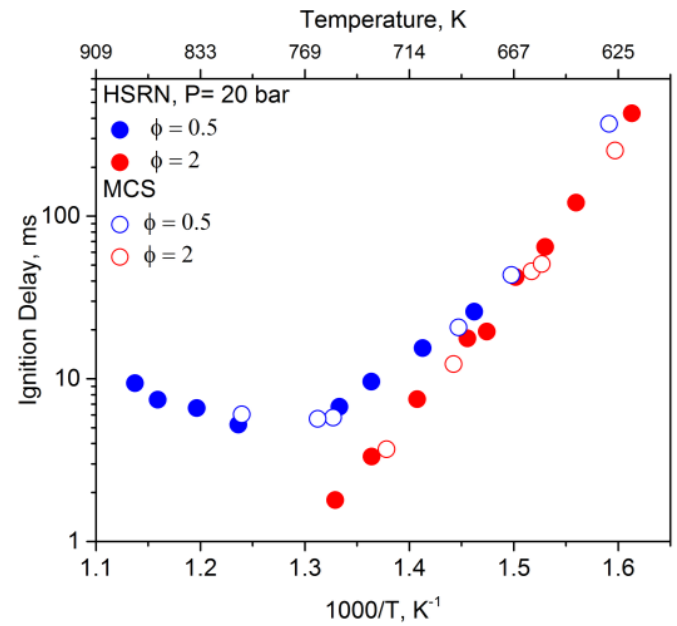

(c)

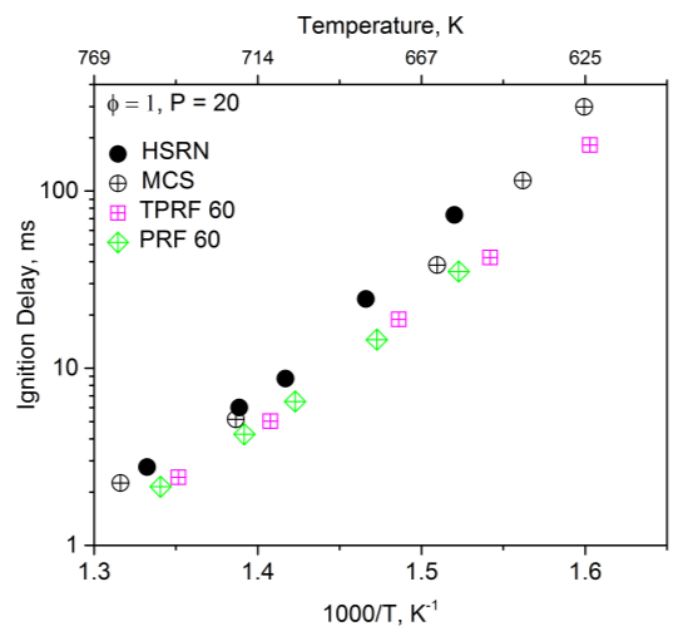

(b)

Fig. 5. Comparison between ignition delay times of HSRN and the three surrogates (PRF 60, TPRF 60 and MCS).

\subsection{Ignition Delay Time Simulations}

Measured ignition delay times are compared with chemical kinetic simulations of PRF 60, TPRF 60 and MCS. The FACE gasolines mechanism developed by Sarathy et al. [41] was used to simulate the MCS, while, unless mentioned otherwise, the gasoline surrogate mechanism by Mehl et al. [42] was used for PRF 60 and TPRF 60 simulations.

Figure 6(a) shows a comparison between HSRN shock tube experimental data and the ignition delay time simulations of the three surrogates. In the high and intermediate temperatures, the simulations of the three surrogates generally agree with the HSRN 
experimental data. However, at low temperatures, the MCS model does a better job in predicting the fuel reactivity compared to the PRF 60 and TPRF 60 surrogate simulations. This observation is clearer in Fig. 6(b) which plots RCM measurements of HSRN and simulations of the three surrogates. Figure 6(c) compares experimental HSRN data at fuel lean and fuel rich conditions with simulations of MCS. The model captures the lean data but exhibits faster reactivity for the rich mixture. Simulations of PRF and TPRF surrogates are not shown in Fig. 6(c) for clarity; however, those simulations will be faster than MCS simulations as seen in Figs. 6(a) and 6(b). These comparisons illustrate the need of multicomponent surrogates for emulating the reactivity of naphtha-like fuels at lower temperatures. An additional point is that the PRF 60 and TPRF 60 surrogate simulations show quite similar reactivity across the range of conditions, and thus there is no advantage of going from two to three component surrogates for fuels with low octane sensitivity such as the HSRN.

At high pressure (60 bar), the TPRF 60 and PRF 60 models show good agreement with the HSRN experimental data at low temperature, while the same models show faster ignition delay times than HSRN at 20 bar. For further investigation, ignition delay times of stoichiometric mixture of PRF 60 were measured in the shock tube at 60 bar. The results show that the experimental PRF data exhibit faster ignition delay times than HSRN and the prediction of PRF model [42]; see Fig. 5(a) and 6(a). The agreement of the PRF and TPRF simulations with the 60 bar HSRN ignition delay data is thus only fortuitous. It may then be argued that the PRF model [42] overestimates the PRF 60 ignition delay time at high pressure ( $60 \mathrm{bar}$ ) and low temperatures. This deficiency may be attributed to the iso-octane chemistry which has recently been revised and presented in the form of an improved model [43]. 


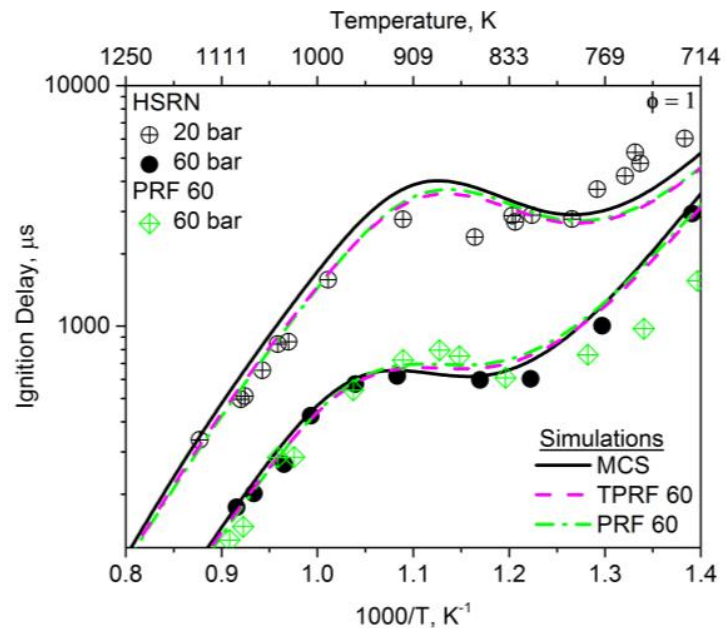

(a)

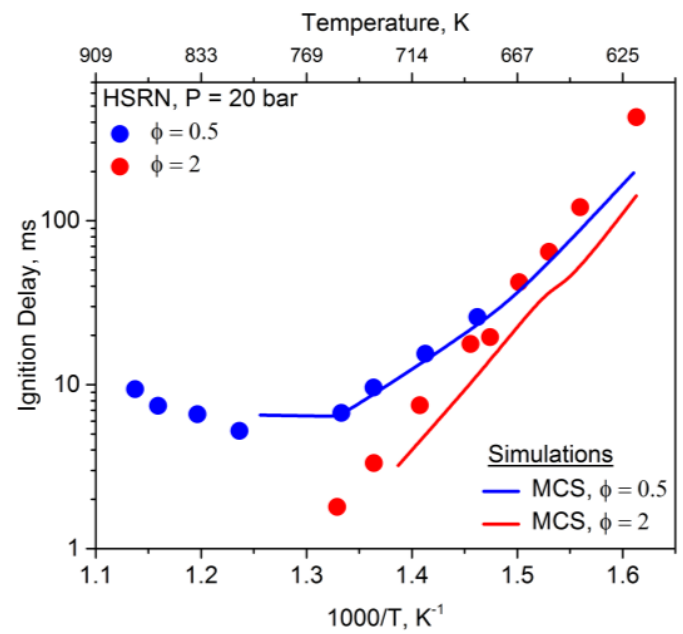

(c)

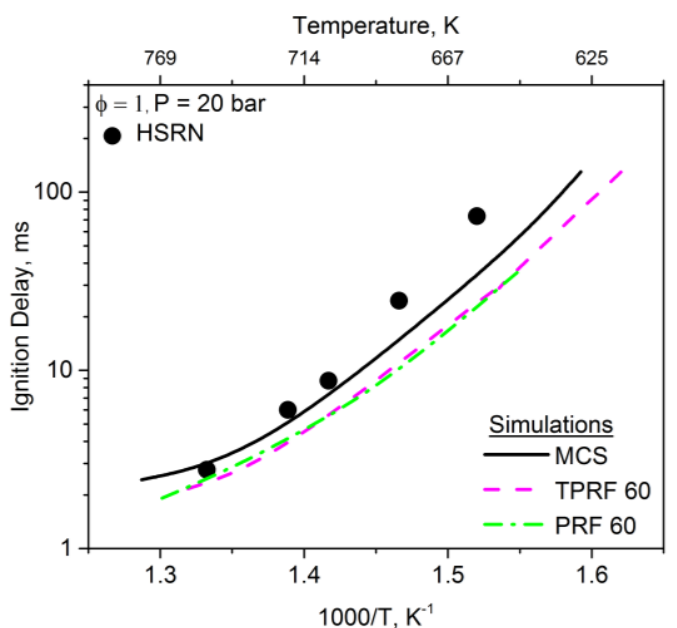

(b)

Fig. 6. Comparison between measured and simulated ignition delay times. (a) Shock tube (b) - (c) RCM. Simulations of MCS (multi-component surrogate) are carried out using Sarathy et al. [41] model. Simulations of PRF 60 and TPRF 60 are carried out using Mehl et al. [42] model.

In summary, multi-components surrogates which represent both the paraffinic and non-paraffinic components of the real fuel are required for capturing the low-temperature reactivity. At high and intermediate temperatures, a two-component surrogate is sufficient to predict the ignition properties of low-sensitivity fuels such as straight run naphtha. This finding has been reported earlier for other fuels such as FACE A and C which have RON of 83.7 and 84.5 respectively [44, 45]. Also, Javed et al. [32] showed that the prediction of PRF model agreed well with light naphtha ignition delay times at high and intermediate 
temperatures. However, at low temperatures, both simulations and experiments showed the PRF surrogate to be more reactive than light naphtha.

\subsection{Low-Temperatures Chemical Kinetic Analysis}

A kinetic analysis was performed to better understand the effects of fuel composition on low temperature ignition behavior of HSRN. This was achieved by comparing the effects of various hydrocarbon components on ignition. It was found that low-temperature ignition behavior of the naphtha fuel displays interesting effects of nonparaffinic components on the overall ignition delay time. For example, comparing the experimentally measured ignition delay times of HSRN ( 10\% aromatics and 15\% cycloalkanes) to TPRF 60 ( 12\% toluene) and PRF 60 (only paraffinic components) indicates that HSRN is less reactive than PRF 60 and TPRF 60. Experimental ignition delay times of PRF 60 and TPRF 60 show minimal differences, as shown in Fig. 5(b); therefore, the effect of cycloalkane low temperature ignition chemistry has a prominent effect on the ignition behavior of HSRN.

Simulated hydroxyl time-history profiles during the oxidation of stoichiometric mixtures of the three surrogates (PRF 60, TPRF 60, and MCS) are presented in Fig. 7 at 20 bar and $650 \mathrm{~K}$. Previous studies by Merchant et al. [46] and others [41, 47, 48] have shown that $\mathrm{OH}$ radical profiles provide insights into the chemical kinetics of ignition processes. The initial growth of $\mathrm{OH}$ radicals is similar between all the fuels, but at $\sim 5 \mathrm{~ms}$ the $\mathrm{OH}$ radical growth for MCS slows compared to that of PRF and TPRF. The latter two fuels display similar $\mathrm{OH}$ radical profiles up to the point of ignition. A local maximum in $\mathrm{OH}$ radical concentration is observed for all the fuels shortly before the main ignition event, which corresponds to the first stage ignition delay time. The slower buildup of $\mathrm{OH}$ concentration for MCS compared to TPRF 60 and PRF 60 results in delayed first and second stage ignition delay times. Temperature and $\mathrm{OH}$ sensitivity analyses, Fig. $8(a)-$ (b), show that the overall reactivity is sensitive to the $\mathrm{H}$-abstraction from fuel molecules by $\mathrm{OH}$ radicals. Toluene $+\mathrm{OH}$ and cyclopentane $+\mathrm{OH}$ appear to have the highest sensitivity coefficient and inhibit the overall reactivity. Sensitivity analysis also shows that the heat release and $\mathrm{OH}$ concentration are sensitive to the isomerization of cyclopentyl peroxy radical (CPTO2J) to QOOH radical (CPT1Q3J). Our previous studies on 
cyclopentane oxidation $[49,50]$ and mixtures comprising cyclopentane $[41,47]$ have explained its ignition characteristics.

Furthermore, hydroxyl $(\mathrm{OH})$ and hydroperoxyl $\left(\mathrm{HO}_{2}\right)$ rate-of-production analyses were performed for the multi-component surrogate, Fig. $8(c)-(d)$. The analyses indicate that the concerted elimination of cyclopentyl peroxy radical (CPTO2J) to cyclopentene and $\mathrm{HO}_{2}$ contribute to the production rate of $\mathrm{HO}_{2}$ - Reaction of $n$-heptane with $\mathrm{OH}$ is the primary sink of $\mathrm{OH}$ radical due to its high concentration and the five secondary carbon atoms which provide easier abstraction than the primary carbon atoms. Interestingly, although cyclopentane is merely 8.7 mole\% in MCS, the analyses show that the reactions involving cyclopentane or its intermediate species play an important role in promoting or inhibiting the overall reactivity of MCS. This illustrates the huge impact of cycloalkane chemistry on the reactivity of multi-component surrogates and distillate fuels at low temperatures.

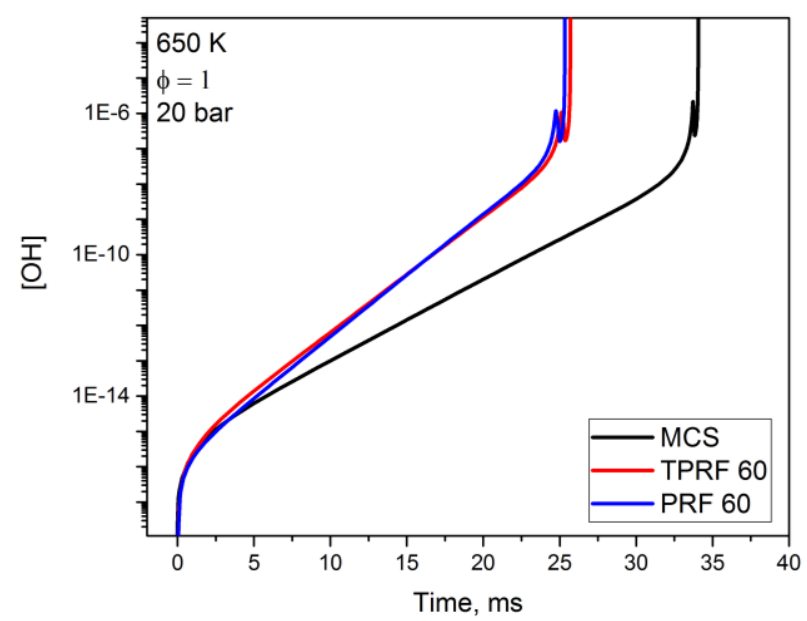

Figure 7. Hydroxyl concentration-time history during the oxidation of stoichiometric mixtures of MCS, TPRF 60 and PRF 60. Simulations carried out using Sarathy et al. [41]
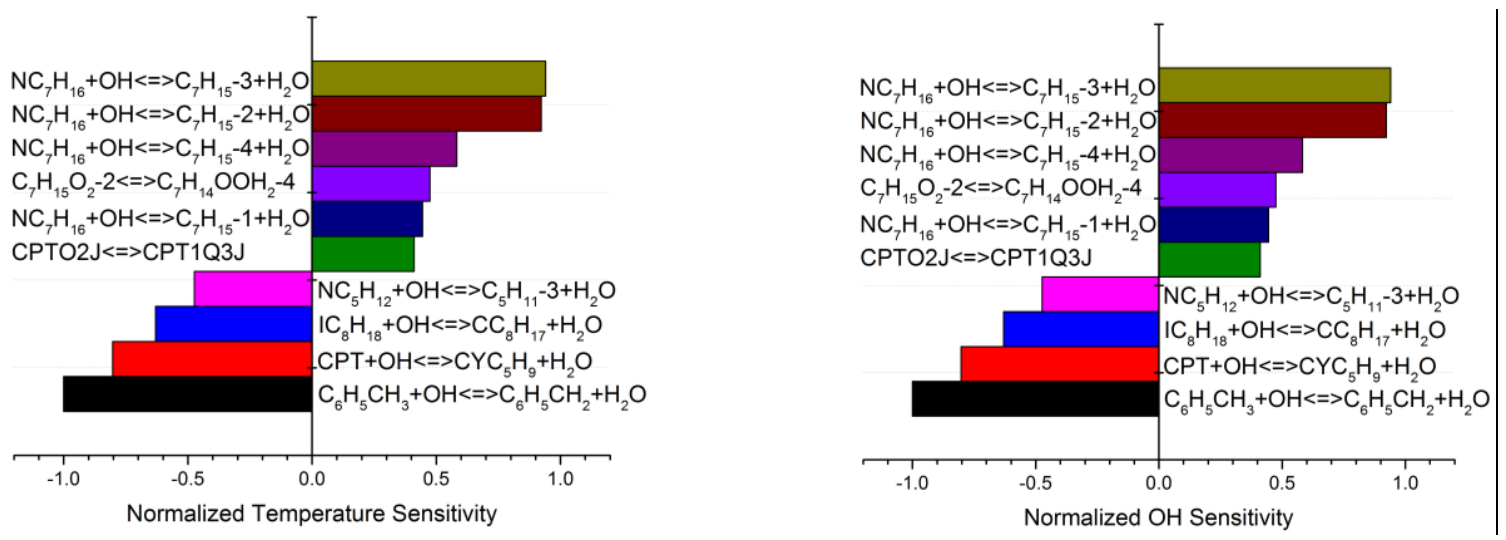
(a)

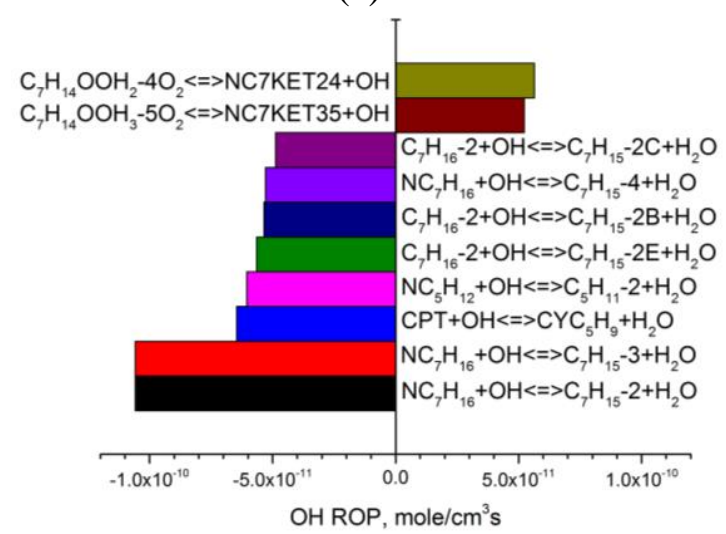

(c) (b)

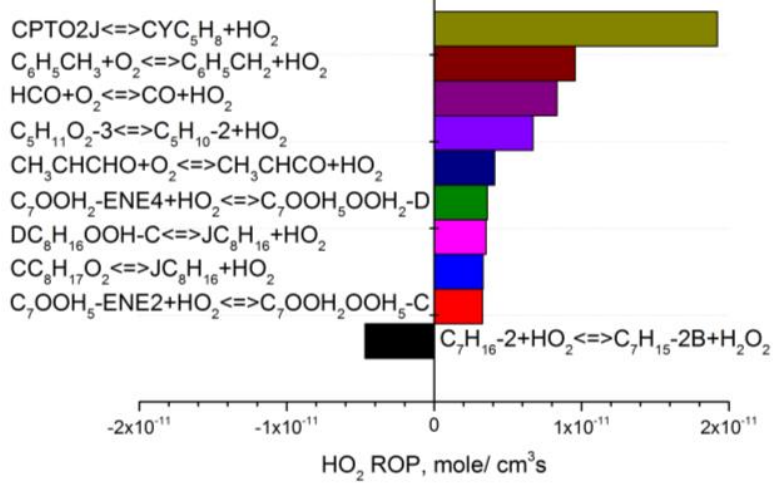

(d)

Figure 8. Normalized sensitivity and (a) Temperature sensitivity analysis, (b) Hydroxyl sensitivity analysis, (c) Hydroxyl rate-of-production analysis, (d) Hydroperoxyl rate-ofproduction analysis. Analyses carried out at $650 \mathrm{~K}, 20$ bar and $\phi=1$ for the MCS using Sarathy et al. [41]. Sensitivity analysis is given at the time of ignition and rate-ofproduction analyses are at $25 \%$ of total ignition delay.

Ignition delay time simulations of the six constituents of MCS are provided in Figure S1(a) (Supplementary Materials). Interestingly, although the ignition delay time of toluene are longer than cyclopentane, our simulations and as well our experimental data shows that the overall fuel reactivity is more inhibited by the presence of cycloalkanes (cyclopentane) than aromatics (toluene). This point is further elaborated in Figure S1(b) (Supplementary Materials) which shows the effect of replacing toluene by cyclopentane in the TPRF 60 mixture. Again, despite that the ignition delay time of toluene being longer than cyclopentane, the total ignition delay times are longer for cyclopentane + PRF than toluene + PRF in the NTC and low temperatures. These results clearly indicate the inhibiting chemistry effects of cyclopentane at low temperatures. This is because abstraction of cyclopentane $\mathrm{H}$ atoms is fast, but the formed cyclopentyl radical's subsequent reaction with $\mathrm{O}_{2}$ does not lead to low temperature $\mathrm{OH}$ radical chain branching; rather $\mathrm{HO}_{2}$ radical formation is favored in cyclopentane. In mixtures, cyclopentane acts as a sink for $\mathrm{OH}$ radicals, as shown in previous work on FACE gasoline surrogate ignition kinetics [41]. At higher temperatures, the effect of fuel composition is minimal because the oxidation process is dominated by the decomposition of $\mathrm{H}_{2} \mathrm{O}_{2}$ to form two $\mathrm{OH}$ radicals and by the $\mathrm{H}+\mathrm{O}_{2}$ chain branching reaction. 


\subsection{Engine Simulations}

The similarities and differences between the homogeneous ignition delay times of the multi-component and PRF surrogates were further explored with zero-dimensional engine simulations in Chemkin-Pro using the FACE gasoline kinetic mechanism [41] for the multi-component surrogate (MCS) and the gasoline surrogate mechanism [42] for PRF 60 surrogate. Heat transfer was not taken into consideration in the engine simulations. Engine operating conditions were chosen to investigate the differences between multicomponent and PRF surrogates at high and low values of temperature, pressure and engine load. In each case, the simulation was started at the start of injection, and instantaneous mixing of fuel and air was assumed.

To choose relevant boundary conditions, computational fluid dynamic (CFD) simulations (not reported here) were carried out for representing low-emissions, light-duty, gasoline compression-ignition (GCI) engine [51]. The modelled engine has a compression ratio of $14.5: 1$ and the engine speed is kept constant at 1500 RPM. A relatively early injection, partially-premixed combustion strategy was considered for the low-load (6 bar indicated mean effective pressure, IMEP) case A. On the other hand, Case $\mathrm{C}$ with high load (18 bar IMEP) represents late injection, diffusion combustion. An HCCI scenario (Case B) was also modelled with the start of injection (SOI) being at intake valve closure (IVC), corresponding to a load of 10 bar IMEP. More details about the three light-duty engine cases are listed in Table 2 . These light duty GCI cases were explored by varying the IVC temperature for each condition from 300 to $450 \mathrm{~K}$. The engine parameters and boundary conditions for each case are provided in the Supplementary Material.

\begin{tabular}{|c|c|c|c|c|c|c|c|}
\hline Case & $\begin{array}{c}\text { Load (bar } \\
\text { IMEP) }\end{array}$ & $\begin{array}{c}\text { IVC } \\
\text { T (K) }\end{array}$ & $\begin{array}{c}\text { SOI } \\
(\mathrm{CAD})\end{array}$ & $\begin{array}{c}\text { P } \\
(\mathrm{bOr})\end{array}$ & $\begin{array}{c}\text { TSOI } \\
(\mathrm{K})\end{array}$ & $\varphi$ & $\begin{array}{c}\mathrm{x}_{\mathrm{O} 2} /\left(\mathrm{x}_{\text {inert }}+\right. \\
\left.\mathrm{x}_{\mathrm{O} 2}\right) \\
(\mathrm{mol} / \mathrm{mol})\end{array}$ \\
\hline $\mathrm{A}$ & 6 & 363 & -42 & 9.7 & 617 & 0.56 & 0.133 \\
\hline $\mathrm{B}$ & 10 & 343 & -162 & 3.3 & 343 & 0.30 & 0.149 \\
\hline C & 18 & 343 & -1 & 156 & 1083 & 0.54 & 0.149 \\
\hline
\end{tabular}

Table 2. Summary of boundary conditions used to represent the light-duty GCI engine operating conditions. 
For each of the 0-D simulation cases, following analysis was carried out. Accumulated heat release was compared against heat of combustion reported in the literature [52], and only those cases which achieved at least $50 \%$ of literature heat release were considered. The fractional accumulated heat release was then analyzed to determine crank angle of $0.1 \%, 2 \%$, and $50 \%$ (CA50) heat release. The temperature at $0.1 \%$ heat release was used to determine the temperature at the start of combustion, whereas CA50 was used as a measure of the relative reactivity of the two surrogates. To determine any potential impact of the thermodynamic properties of the surrogate on the combustion behavior, pre-combustion temperatures (at -40 CAD) were compared for the 10 bar HCCI case. As shown in Fig. S2 (Supplementary Material), the differences in temperatures at $40 \mathrm{CAD}$ were less than $2 \mathrm{~K}$ in all cases. To further illustrate the same point, Fig. S3 (Supplementary Material) plots the bulk-gas in-cylinder temperature profiles for both surrogates with an intake temperature of $320 \mathrm{~K}$. Although the two surrogates show considerable difference in CA50, the pre-combustion temperature profiles are identical for the two surrogates.

Figure 9 shows the results for the difference in CA50 for the two surrogates at the various light-duty GCI operating points as a function of start of combustion temperature (resulting from different intake temperatures). Several observations can be made from these data. First, the 10 bar HCCI data set (Case B) has categorically lower start of combustion temperatures. This is due to the fact that the fuel has more time to react (the simulation starts at IVC) and that the presence of fuel during the compression stroke changes the thermodynamic properties of the gas mixture, resulting in lower precombustion bulk gas temperatures at a given crank angle. Importantly, it may be observed that in all three cases, lower start of combustion temperatures correlate with greater deviations in the predicted CA50 for the PRF and multi-component surrogate (MCS). This is because of the observed differences between the ignition delay times of PRF and MCS at low temperatures (Section 3.1). The CA50 of PRF and MCS are very similar when the start of combustion temperatures are higher than $1000 \mathrm{~K}$. this is also in agreement with what was observed earlier from the IDT curves where PRF and MCS exhibited nearly identical IDTs at high temperatures. 


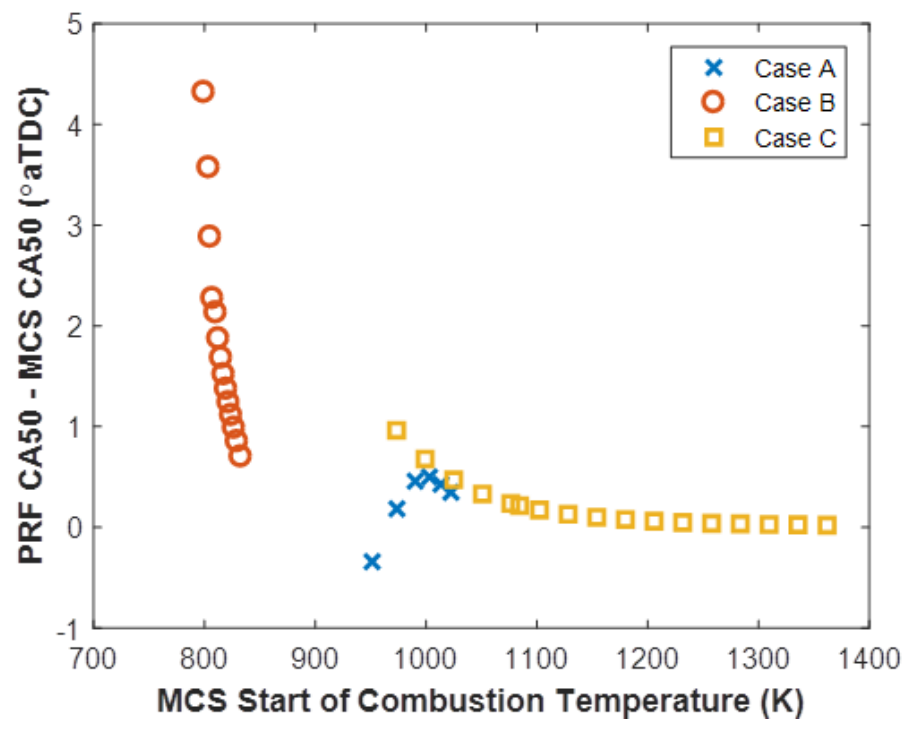

Fig. 9. Difference in CA50 for the multi-components (MCS) and PRF surrogates at the light-duty GCI operating conditions at different IVC temperatures.

In summary, the PRF and MCS surrogates showed different reactivity behavior under intermediate temperature conditions $(\sim 800 \mathrm{~K})$, as evidenced by significant differences in CA50. At higher start of combustion temperatures (>1000 K), the reactivity converged to the point where the differences in CA50 were negligible. These results suggest that a complex fuel surrogate is needed for more accurate predictions of the combustion behavior in engines employing low-temperature combustion strategy, particularly under low-load conditions. On the other hand, PRF surrogates can be safely used at high loads where high combustion pressures and temperatures are expected.

\section{Conclusions}

Ignition delay times for a straight run naphtha fuel (HSRN) were measured in a shock tube and a rapid compression machine over wide ranges of conditions. Expected influences of pressure and equivalence ratio were observed where ignition delay times exhibited strongest sensitivity to $\mathrm{P}$ and $\phi$ in the NTC region. These measurements were compared with experimental and simulated ignition delay times of three chemical kinetic surrogates - a two-component PRF surrogate, a 3-component TPRF surrogate and a six-component 
surrogate. All three surrogates captured the reactivity of HSRN at high and intermediate temperatures. However, at low temperatures $(<700 \mathrm{~K})$, PRF and TPRF surrogates exhibited faster reactivity compared to HSRN while the multi-component surrogate fared much better.

Sensitivity and rate of production analyses indicate that cyclopentane acts as a sink of $\mathrm{OH}$ radicals and inhibits the the overall system reactivity. The absence of cyclopentane in PRF and TPRF surrogates thus makes these fuels more reactive than HSRN and multicomponent surrogate which contain naphthenic compounds. Zero-dimensional engine simulations indicate that PRF can be used as an adequate surrogate of HSRN under highload conditions which result in relatively high start-of-combustion temperatures. However, multi-component surrogate would be needed to model engine performance and combustion phasing at low engine loads where low-temperature kinetics play appreciable role.

\section{Acknowledgement:}

Research reported in this publication was funded by Saudi Aramco under the FUELCOM program and by King Abdullah University of Science and Technology (KAUST). 


\section{Supplementary Materials:}

Appendix 1:

Table S1. Properties of the palette species used for HSRN surrogate formulation.

Table S2. Compositions of PRF 60, TPRF 60 and MCS.

Table S3. Suppliers and purities of the surrogate components used in the ignition delay time measurements of the MCS (multi-component surrogate).

Table S4. Measured ignition delay times and corresponding conditions.

Figure S1. Ignition delay time simulation using Sarathy et al. [41] mechanism. (a) Comparison between the multicomponent surrogate and its components, (b) Effect of toluene and cyclopentane to the reactivity of PRF surrogate. Constant volume reactor is assumed for these simulations. $\mathrm{P}=20$ bar, $\phi=1$.

Figure S2. Comparison of bulk-gas temperature at $-40 \mathrm{CAD}$ in the 10 bar HCCI combustion cases (SOI = -162) for the multi-component (MCS) and PRF surrogates.

Figure S3. Bulk-gas temperature profiles for the PRF and multi-component surrogates at the light-duty GCI 10 bar operating point with $320 \mathrm{~K}$ IVC temperature.

Detailed Hydrocarbon Analysis (DHA) for Haltermann Straight-run Naphtha. Certificate of Analysis (CofA) for Haltermann Straight-run Naphtha (HSRN).

\section{Appendix 2:}

Spreadsheet: Zero-dimension engine simulation parameters and conditions. 


\section{References:}

[1] International Energy Outlook 2014: World Petroleum and Other Liquid Fuels, U.S. Energy Information Administration (EIA), Washington, DC 20585, 2014.

[2] ExxonMobil, Explore the Outlook for Energy: A View to 2040, 2016.

[3] T. Li, R. Moriwaki, H. Ogawa, R. Kakizaki, M. Murase, Dependence of premixed low-temperature diesel combustion on fuel ignitability and volatility, International Journal of Engine Research 13 (2011) 14-27.

[4] World Energy Outlook 2014, International Energy Agency2014.

[5] C.L. Xu, L. Bell, Global reserves, oil production show increases for 2014, Oil Gas J. 112 (2014) 30-31.

[6] H. Zhao, HCCI and CAI engines for the automotive industry, Elsevier2007.

[7] R.M. Hanson, S.L. Kokjohn, D.A. Splitter, R.D. Reitz, An Experimental Investigation of Fuel Reactivity Controlled PCCI Combustion in a Heavy-Duty Engine, SAE Int. J. Engines 3 (2010) 700-716.

[8] R.D. Reitz, G. Duraisamy, Review of high efficiency and clean reactivity controlled compression ignition (RCCI) combustion in internal combustion engines, Progress in Energy and Combustion Science 46 (2015) 12-71.

[9] A. Ickes, T. Wallner, Y. Zhang, W. De Ojeda, Impact of Cetane Number on Combustion of a Gasoline-Diesel Dual-Fuel Heavy-Duty Multi-Cylinder Engine, SAE Int. J. Engines 7 (2014) 860-872.

[10] Y. Viollet, J. Chang, G. Kalghatgi, Compression Ratio and Derived Cetane Number Effects on Gasoline Compression Ignition Engine Running with Naphtha Fuels, SAE International Journal of Fuels and Lubricants 7 (2014) 412-426.

[11] G. Kalghatgi, P. Risberg, H. Ångström, Advantages of fuels with high resistance to autoignition in late-injection, low-temperature, compression ignition combustion, SAE Technical Paper 2006-01-3385, (2006).

[12] J. Badra, A. Elwardany, J. Sim, Y. Viollet, H.G. Im, J. Chang, Effects of In-Cylinder Mixing on Low Octane Gasoline Compression Ignition Combustion, SAE Technical Paper 2016-01-0762, doi:10.4271/2016-01-0762(2016).

[13] J.A. Badra, J. Sim, A. Elwardany, M. Jaasim, Y. Viollet, J. Chang, A. Amer, H.G. Im, Numerical Simulations of Hollow-Cone Injection and Gasoline Compression Ignition Combustion With Naphtha Fuels, Journal of Energy Resources Technology 138 (2016) 052202-052202.

[14] V. Manente, C.-G. Zander, B. Johansson, P. Tunestal, W. Cannella, An Advanced Internal Combustion Engine Concept for Low Emissions and High Efficiency from Idle to Max Load Using Gasoline Partially Premixed Combustion, SAE Technical Paper 2010-01-2198, doi:doi:10.4271/2010-01-2198(2010).

[15] M. Sellnau, M. Foster, K. Hoyer, W. Moore, J. Sinnamon, H. Husted, Development of a Gasoline Direct Injection Compression Ignition (GDCI) Engine, SAE Int. J. Engines 7 (2014) 835-851.

[16] G.T. Kalghatgi, L. Hildingsson, A.J. Harrison, B. Johansson, Autoignition quality of gasoline fuels in partially premixed combustion in diesel engines, Proc. Combust. Inst. 33 (2011) 3015-3021.

[17] G.T. Kalghatgi, P. Risberg, H.-E. Ångström, Partially Pre-Mixed Auto-Ignition of Gasoline to Attain Low Smoke and Low NOx at High Load in a Compression Ignition 
Engine and Comparison with a Diesel Fuel, SAE Technical Paper 2007-01-0006, SAE International, 2007.

[18] S. Ciatti, S.N. Subramanian, An Experimental Investigation of Low-Octane Gasoline in Diesel Engines, Journal of Engineering for Gas Turbines and Power 133 (2011) 092802-092802.

[19] G. Kalghatgi, L. Hildingsson, B. Johansson, Low NOx and Low Smoke Operation of a Diesel Engine Using Gasolinelike Fuels, Journal of Engineering for Gas Turbines and Power 132 (2010) 092803-092803.

[20] A.M. Ickes, S.V. Bohac, D.N. Assanis, Effect of fuel cetane number on a premixed diesel combustion mode, International Journal of Engine Research 10 (2009) 251-263. [21] R.F. Cracknell, D.J. Rickeard, J. Ariztegui, K.D. Rose, M. Muether, M. Lamping, A. Kolbeck, Advanced Combustion for Low Emissions and High Efficiency Part 2: Impact of Fuel Properties on HCCI Combustion, SAE International, 2008.

[22] K. Akihama, H. Kosaka, Y. Hotta, K. Nishikawa, K. Inagaki, T. Fuyuto, Y. Iwashita, J.T. Farrell, W. Weissman, An Investigation of High Load (Compression Ignition) Operation of the "Naphtha Engine" - a Combustion Strategy for Low Well-to-Wheel CO2 Emissions, SAE Int. J. Fuels Lubr. 1 (2008) 920-932.

[23] A. Weall, N. Collings, Investigation into Partially Premixed Combustion in a LightDuty Multi-Cylinder Diesel Engine Fuelled Gasoline and Diesel with a Mixture of, SAE International, 2007.

[24] F. Zhang, H. Xu, S. Zeraati Rezaei, G. Kalghatgi, S.-J. Shuai, Combustion and Emission Characteristics of a PPCI Engine Fuelled with Dieseline, SAE International, 2012.

[25] J. Chang, G. Kalghatgi, A. Amer, P. Adomeit, H. Rohs, B. Heuser, Vehicle Demonstration of Naphtha Fuel Achieving Both High Efficiency and Drivability with EURO6 Engine-Out NOx Emission, SAE Int. J. Engines 6 (2013) 101-119.

[26] Y. Zhang, A. Voice, T. Tzanetakis, M. Traver, D. Cleary, An Evaluation of Combustion and Emissions Performance With Low Cetane Naphtha Fuels in a Multicylinder Heavy-Duty Diesel Engine, Journal of Engineering for Gas Turbines and Power 138 (2016) 102805-102805.

[27] G. Kalghatgi, L. Hildingsson, A. Harrison, B. Johansson, Surrogate fuels for premixed combustion in compression ignition engines, International Journal of Engine Research, (2011) 452-465.

[28] K.D. Rose, R.F. Cracknell, D.J. Rickeard, J. Ariztegui, W. Cannella, N. Elliott, H. Hamje, M. Muether, T. Schnorbus, A. Kolbeck, M. Lamping, Impact of Fuel Properties on Advanced Combustion Performance in a Diesel Bench Engine and Demonstrator Vehicle, SAE International, 2010.

[29] N. Naser, M. Jaasim, N. Atef, S.H. Chung, H.G. Im, S.M. Sarathy, On the effects of fuel properties and injection timing in partially premixed compression ignition of low octane fuels, Fuel 207 (2017) 373-388.

[30] P.C. Bakker, J.E. De Abreu Goes, L.M.T. Somers, B.H. Johansson, Characterization of Low Load PPC Operation using RON70 Fuels, SAE International, 2014.

[31] L. Hildingsson, B. Johansson, G.T. Kalghatgi, A.J. Harrison, Some Effects of Fuel Autoignition Quality and Volatility in Premixed Compression Ignition Engines, SAE Int. J. Engines 3 (2010) 440-460. 
[32] T. Javed, E.F. Nasir, A. Ahmed, J. Badra, K. Djebbi, M. Beshir, W. Ji, S.M. Sarathy, A. Farooq, Ignition delay measurements of light naphtha: A fully blended low octane fuel, Proc. Combust. Inst. 36 (2017) 315-322.

[33] H. Hao, F. Liu, Z. Liu, F. Zhao, Compression ignition of low-octane gasoline: Life

cycle energy consumption and greenhouse gas emissions, Applied Energy 181 (2016) 391-398.

[34] G. Kalghatgi, H. Babiker, J. Badra, A simple method to predict knock using toluene, n-heptane and iso-octane blends (TPRF) as gasoline surrogates, SAE International Journal of Engines 8 (2015) 505-519.

[35] J. Badra, Y. Viollet, A. Elwardany, H.G. Im, J. Chang, Physical and chemical effects of low octane gasoline fuels on compression ignition combustion, Applied Energy 183 (2016) 1197-1208.

[36] A. Ahmed, G. Goteng, V.S. Shankar, K. Al-Qurashi, W.L. Roberts, S.M. Sarathy, A computational methodology for formulating gasoline surrogate fuels with accurate physical and chemical kinetic properties, Fuel 143 (2015) 290-300.

[37] E.W. Lemmon, M.L. Huber, M.O. McLinden, NIST reference fluid thermodynamic and transport properties-REFPROP, NIST standard reference database 23 (2002) v7. [38] R.J. Kee, F.M. Rupley, J.A. Miller, The Chemkin thermodynamic data base, Report No. SAND-87-8215B, Sandia National Lab, Livermore, CA (USA), [39] M. AlAbbad, T. Javed, F. Khaled, J. Badra, A. Farooq, Ignition delay time measurements of primary reference fuel blends, Combust. Flame 178 (2017) 205-216. [40] J. Würmel, J.M. Simmie, H.J. Curran, Studying the chemistry of HCCI in rapid compression machines, International Journal of Vehicle Design 44 (2007) 84-106. [41] S.M. Sarathy, G. Kukkadapu, M. Mehl, T. Javed, A. Ahmed, N. Naser, A. Tekawade, G. Kosiba, M. AlAbbad, E. Singh, S. Park, M.A. Rashidi, S.H. Chung, W.L. Roberts, M.A. Oehlschlaeger, C.-J. Sung, A. Farooq, Compositional effects on the ignition of FACE gasolines, Combust. Flame 169 (2016) 171-193.

[42] M. Mehl, W.J. Pitz, C.K. Westbrook, H.J. Curran, Kinetic modeling of gasoline surrogate components and mixtures under engine conditions, Proc. Combust. Inst. 33 (2011) 193-200.

[43] N. Atef, G. Kukkadapu, S.Y. Mohamed, M.A. Rashidi, C. Banyon, M. Mehl, K.A. Heufer, E.F. Nasir, A. Alfazazi, A.K. Das, C.K. Westbrook, W.J. Pitz, T. Lu, A. Farooq, C.-J. Sung, H.J. Curran, S.M. Sarathy, A comprehensive iso-octane combustion model with improved thermochemistry and chemical kinetics, Combust. Flame 178 (2017) 111134.

[44] S.M. Sarathy, G. Kukkadapu, M. Mehl, W. Wang, T. Javed, S. Park, M.A. Oehlschlaeger, A. Farooq, W.J. Pitz, C.-J. Sung, Ignition of alkane-rich FACE gasoline fuels and their surrogate mixtures, Proc. Combust. Inst. 35 (2015) 249-257.

[45] B. Chen, C. Togbé, Z. Wang, P. Dagaut, S.M. Sarathy, Jet-stirred reactor oxidation of alkane-rich FACE gasoline fuels, Proc. Combust. Inst. 36 (2017) 517-524.

[46] S.S. Merchant, C.F. Goldsmith, A.G. Vandeputte, M.P. Burke, S.J. Klippenstein, W.H. Green, Understanding low-temperature first-stage ignition delay: Propane, Combust. Flame 162 (2015) 3658-3673.

[47] E. Singh, J. Badra, M. Mehl, S.M. Sarathy, Chemical Kinetic Insights into the Octane Number and Octane Sensitivity of Gasoline Surrogate Mixtures, Energy \& Fuels 31 (2017) 1945-1960. 
[48] M. Lapuerta, J.J. Hernández, S.M. Sarathy, Effects of methyl substitution on the auto-ignition of C16 alkanes, Combust. Flame 164 (2016) 259-269.

[49] M.J. Al Rashidi, M. Mehl, W.J. Pitz, S. Mohamed, S.M. Sarathy, Cyclopentane combustion chemistry. Part I: Mechanism development and computational kinetics, Combust. Flame 183 (2017) 358-371.

[50] M.J. Al Rashidi, J.C. Mármol, C. Banyon, M.B. Sajid, M. Mehl, W.J. Pitz, S. Mohamed, A. Alfazazi, T. Lu, H.J. Curran, Cyclopentane combustion. Part II. Ignition delay measurements and mechanism validation, Combust. Flame, (2017).

[51] Y. Zhang, Y. Pei, N. Engineer, K. Cho, D. Cleary, CFD-Guided Combustion

Strategy Development for a Higher Reactivity Gasoline in a Light-Duty Gasoline Compression Ignition Engine, Report No. 0148-7191, SAE Technical Paper, 2017. [52] J.-C. Guibet, E. Faure-Birchem, Fuels and engines: technology, energy, environment, Editions Technip1999. 